\title{
STUDY OF KINETIC FORMATION AND THE ELECTROCHEMICAL BEHAVIOR OF POLYPYRROLE FILMS
}

\author{
ÁLVARO A. ARRIETA ALMARIO ${ }^{a}{ }^{*}$, ROSA L. TARAZONA CÁCERES ${ }^{b}$ \\ ${ }^{a}$ DANM/ Development and Application of New Materials. Pontificia Bolivariana University - \\ Montería. Km. 8 vía Cereté. Montería - Córdoba, Colombia. \\ ${ }^{b}$ Faculty of Electronic Engineering, Architecture and Engineering School. Pontificia Bolivariana University - Montería. Km. 8 vía Cereté. \\ Montería - Córdoba. Colombia \\ (Received 23 January 2008 - Accepted 10 July 2008)
}

\begin{abstract}
Polypyrrole films have been electrochemically polymerized on platinum electrode under different conditions. The effect of the parameters used during the potentiostatic polymerization, such as monomer concentration, type of doping agent (i.e. counterion), deposition time (i.e. films thickness), concentration of doping agent and polymerization potential on the rate of growth and the electrochemical properties of the polymeric film has been studied. In addition, the effect of the sweep rate of polypyrrole films polymerized with several doping agents were investigated. The results show that the kinetic of formation, the shape, the peak intensity, the peak potential and the electrochemical stability of the electroactive polypyrrole film are reliant on the conditions used during the polymerization process. The empirical kinetics determined from the polymerization charge were found to depend on $[P y]^{0.85}$ and $\left[\mathrm{SO}_{4}^{2-}\right]^{0.5}$. The kinetic of the electrochemical response was also affected by the anion use as doping agent during the electrochemical synthesis.
\end{abstract}

Keywords: Polypyrrole; Electropolymerization; electrochemical properties; kinetic of formation.

\section{INTRODUCTION}

In recent years, conducting polymers have attracted considerable attention not only out of fundamental scientific interest but also from a practical viewpoint for a variety of potential applications. Many of these materials, have already found applications as electronic devices ${ }^{1-3}$, sensors for electronic tongues ${ }^{4,5}$, selective membranes ${ }^{6}$, and rechargeable batteries ${ }^{7}$. Polypyrrole $(P P y)$ is one of the most extensively studied conducting polymer due to its good electrical conductivity, environment stability, good solubility, redox properties and relative ease oxidation of the monomer (pyrrole).

Polypyrrole can be prepared either by chemical or electrochemical polymerization. In the electrochemical polymerization, the pyrrole $(P y)$ is oxidized by a simple anodic oxidation to produce the polymer films. Polypyrrole generated by electropolymerization method can easily be formed as a strong adherent to various substrates smooth film, possessing good mechanical properties and environment stability. The electrochemical polymerization is of particular interest in that the polymer synthesized in this way is formed directly on the electrode surface, so it is possible to study the electrogeneration mechanism, and the structure, thickness and electrochemical properties of the resulting PPy film are better controlled during the film generation.

The electrical and physical properties of the polymeric films are considerably influenced by the conditions under which they are prepared, such as the electrochemical method of polymerization, concentration of monomer and doping agent and other synthesis conditions ${ }^{8-10}$. Therefore, a great effort must be made in order to find optimum electropolymerization conditions and to obtain polymers with the adequate properties to be used in a wide range of reactions and experimental conditions. In spite of the great number of work carried out about the study of the conducting polymer, there are still some differences between the results reported in the literature. Therefore, research on the preparation and characterization of conducting polymers is ongoing. Studies have been conducted by several research groups on the effect of the preparation conditions on the electrical conductivity of the conducting polymers ${ }^{11,12}$. However, the influence on kinetic formation and electrochemical behavior has not been thoroughly studied so far.

The focus in this investigation is study the influence that some parameters used during the electrochemical polymerization may have on electrochemical behavior and the growth rate of electroactive polypyrrole film. For this purpose, in this contribution we report a systematic study of electrochemical responses and kinetic formation as a function of polypyrrole film prepared potentiostatically under a range of conditions (e.g. potential of polymerization, monomer and doping agent concentrations, polymerization time and type of doping agent).

\section{EXPERIMENTAL}

All chemical used were of analytical reagent grade from Aldrich-Sigma and were used without further purification. The solutions were obtained by solving substances in ultra-pure water.

The polypyrrole films were deposited on working electrodes from platinum disk which was polished with $0.3 \mu \mathrm{m}$ alumina suspension using a microcloth polished pad and rinse with deionised water in an ultrasonic bath for $30 \mathrm{~min}$ to remove any residue. The auxiliary electrode used during the polymerization was a platinum gauze, during the voltammetric experiment, the auxiliary electrode was a conventional platinum electrode. The potentials were referred to an $\mathrm{Ag} / \mathrm{AgCl}$ electrode in a saturated $\mathrm{KCl}$ solution.

The polypyrrole films were electrochemically synthesized in a three electrode glass cell. The electrochemical syntheses were performed potentiostatically at room temperature, using a constant potential $(0.8 \mathrm{~V}$ versus $\mathrm{Ag} / \mathrm{AgCl}$, except in the indicated cases), from an $0.1 \mathrm{~mol} \mathrm{~L}^{-1}$ electrolytic aqueous solution $\left(\mathrm{H}_{2} \mathrm{SO}_{4}\right.$, except in the indicated cases) and $0.2 \mathrm{~mol} \mathrm{~L}^{-1}$ pyrrole (except in the indicated cases) with $\mathrm{pH}$ about 6.5 . Once prepared, the polymeric films were extracted from the solution and washed thoroughly prior to use. The polypyrrole films were used as the working electrode in the cyclic voltammetry experiments. The thickness of the PPy films was estimated according to Diaz et. al. ${ }^{13}$.

All of the electrochemical measurements were performed at room temperature using a potentiostat/galvanostat (Model 2263 SYS, EG\&G from Princeton Applied Research) and recorded on a computer. The voltammograms were carried out at sweep rate of $0.1 \mathrm{~V} \mathrm{~s}^{-1}$ in a scan range from $-1.0 \mathrm{~V}$ to $0.5 \mathrm{~V}$ in a $\mathrm{KCl}$ aqueous solution $0.1 \mathrm{~mol} \mathrm{~L}-1$ with $\mathrm{pH}$ 6.5. It must be emphasized that during the first cycles, the voltammograms varied somewhat, but subsequent scans were highly reproducible and after five scans, the only noticeable change was a small and gradual decrease of the intensity of the peaks. For this reason, the cyclic voltammograms showed in the figures correspond to the fifth cycle unless otherwise specified.

\section{RESULTS AND DISCUSSION}

\section{Influence of the doping agent}

To study the effect of the doping agent on the kinetic formation and the electrochemical behavior of polypyrrole films a range of doping solutions were used: silicotungstate $\left(\mathrm{Si}^{3} \mathrm{~W}^{3-}\right)$, dodecylbenzenesulfonate $\left(D B S^{-}\right)$, sulfate $\left(\mathrm{SO}_{4}^{2-}\right)$ and 1,5-naphthalenedisulfonate $\left(N D S^{2}\right)$. The $P P y$ films were polymerized potentiostatically of $0.2 \mathrm{~mol} \mathrm{~L}^{-1}$ pyrrole aqueous solution and $0.1 \mathrm{~mol} \mathrm{~L}^{-1}$ doping agent at $0.8 \mathrm{~V}$. The chronoamperometric curves recorded during the polymerization are shown in figure 1 . The figures show a characteristic stepped of the potentiostatic polymerization: a plateau where the diffusion controlled monomer oxidation and nucleation of the oligomers produced in the solution takes place and a rapid increase of charge density indicating continuous and gradual polymer growth ${ }^{14}$. It can also be observed that the doping agents play a key role in the polymerization process, producing different induction times, mechanisms of nucleation and polymer growth; therefore the polymerization rate varies with each doping agent. The electrochemical yield of the polymerization process, estimated from the electrical charge consumed during 
polymerization (integration of the area under the I-t curve), strongly depends on the electrolyte used as doping agent. For instance, the rate of growth of the $\mathrm{PPy} / \mathrm{SiW}$ film is approximately 4 times higher that the $P P y / D B S$ film (Figure 1 , curves a and d respectively).

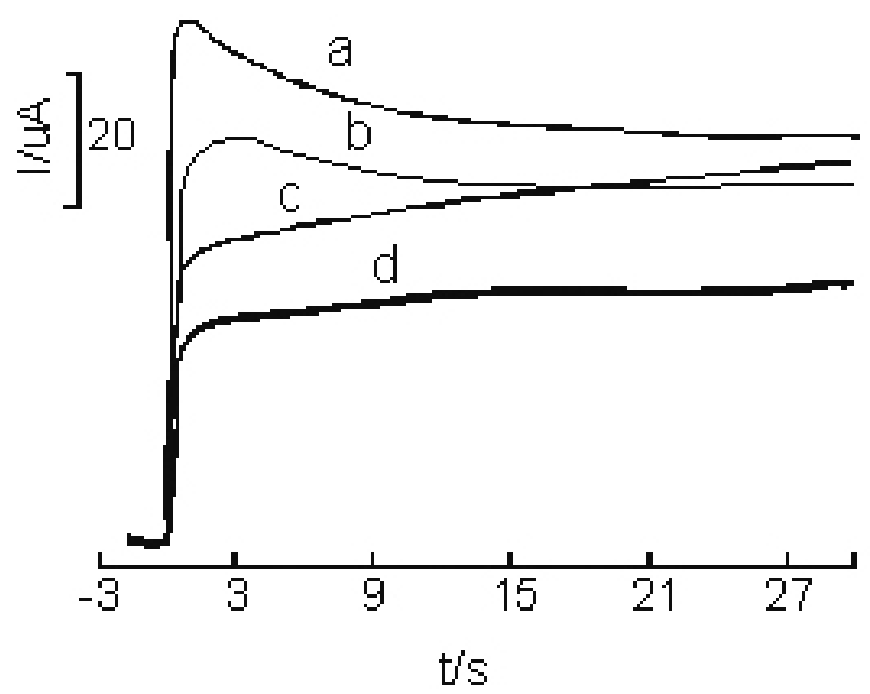

Figure 1: Chronoamperograms of polymerization of $P P y$ in various doping agents: a) $\mathrm{SiW}$, b) $\left.\mathrm{SO}_{4}^{2-}, \mathrm{c}\right) \mathrm{NDS}^{2-}$, d)DBS. Recorded during electrosynthesis at $0.8 \mathrm{~V}$ in solutions of pyrrole/doping agente $\left(0.2 \mathrm{~mol} \mathrm{~L}^{-1} / 0.1 \mathrm{~mol} \mathrm{~L}^{-1}\right)$.

The electrolyte used as doping agent affect the final structure of the film. Thus, the doping agents have a marked influence, not only on the electrochemical yield, but also the electrochemical behavior of the films when exposed to electrolytic solution, providing polypyrrole films with different voltammetric responses.

The electrochemical behavior of polypyrrole films doped with several doping agents towards $\mathrm{KCl} 0.1 \mathrm{~mol} \mathrm{~L}^{-1}$ is illustrated in figure 2. It is important to notice that in all cases, the first scan was slightly different from the subsequent cycle, but subsequent scans were highly reproducible (after five) for this reason, all the curves reported correspond to the sixth scan. The figure shows that each voltammogram showed well defined peaks associated with the electrochemically controlled ion-exchange process. The exact nature of the ion-exchange process is not clearly deciphered, but it has been established that during the first redox process occurring at lower potentials (peak I), the doping anions $\left(X^{*}\right)$ remain immobilized inside the film, whereas cations $\left(C^{+}\right)$are exchanged with the surrounding solution to maintain the electroneutrality. In the second process (peak II), occurring at higher voltages, the PPy film gets highly oxidized and anions $\left(A^{-}\right)$from the electrolyte solution are inserted into the film to maintain the charge balance ${ }^{15-17}$. So, the chemical basis of the electrochemical responses can be explained as follows:

On the first reduction/oxidation process for reasons of electroneutrality, the $P P y$ film behaves as an cation exchanger:

$$
\left[P P y / X^{-} / C^{+}\right]_{f} \stackrel{e^{-}}{\longrightarrow}\left[P P y^{-+} / X^{-}\right]_{f}+\left[C^{+}\right]
$$

The redox reactions leading to the second reduction/oxidation process can be formulated as follows:

$$
\left[P P y^{++} / X^{-}\right]_{f}+\left[A^{-}\right]_{f} \stackrel{e^{-}}{\longrightarrow}\left[P P y^{++} / X^{-} / A^{-}\right]_{f}
$$

In this case, the electroneutrality makes the film behave as a anion exchanger.

The $P P y$ symbolizes a segment of the polypyrrole chain, the subscript [ ] $]_{s}$ indicates that the species is in the solution phase and [ ] is in the PPy matrix.

In figure 2 it can be seen that in all cases, each voltammogram showed well defined peaks associated with the electrochemically controlled ion-exchange process. The $P P y$ films doped with $\left(D B S^{-}\right),\left(N_{D S} S^{2-}\right)$ and $\left(\mathrm{SO}_{4}^{2-}\right)$ immersed in $\mathrm{KCl}$ there were two sets of redox peaks (figure 2_a, 2_b, and 2_c, respectively). This may be attributed to both anion and cation exchange processes being induced at different potentials. The first oxidation/reduction process (cation exchange) were observed at around $-0.63 \mathrm{~V},-0.52 \mathrm{~V}$, and $-0.51 \mathrm{~V}$ respectively.
The anion exchange process were present at around $-0.15 \mathrm{~V}$ for $P P y / D B S$, $0.09 \mathrm{~V}$ for $\mathrm{PPy} / \mathrm{NDS}$, and $-0.10 \mathrm{~V}$ for $\mathrm{PPy} / \mathrm{SO}_{4}$.
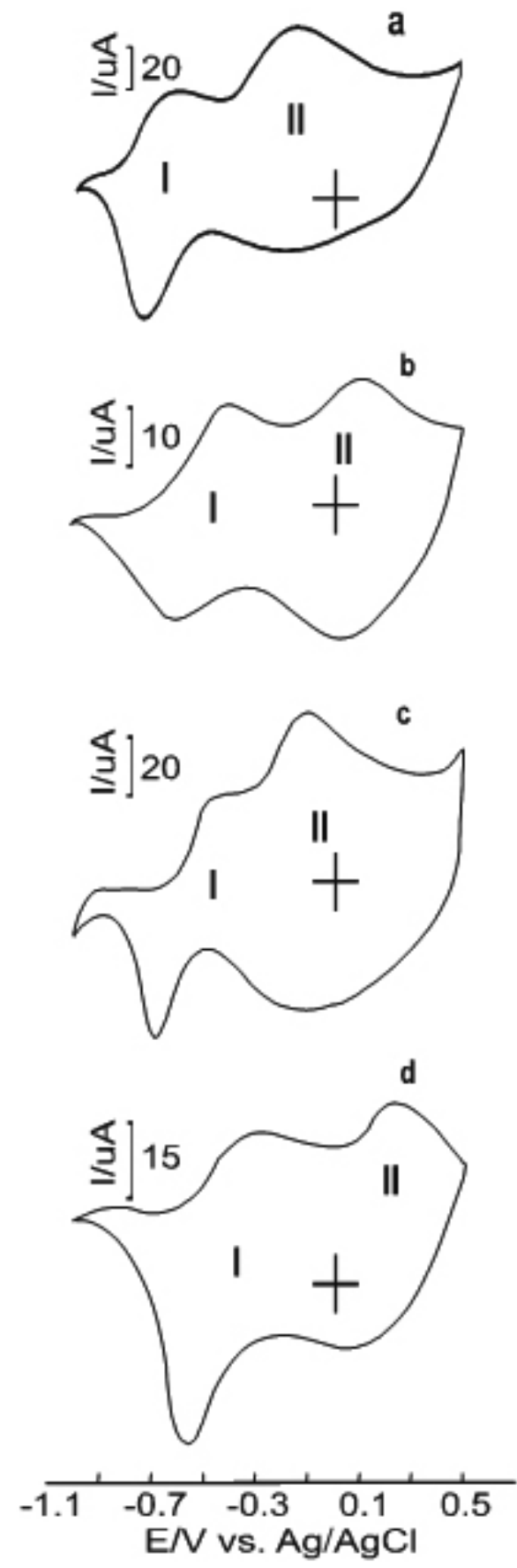

Figure 2: Cyclic voltammograms of: a) $P P y / D B S$, b) $P P y / N D S$, c) $P P y / S_{4}$, d) $P P y / S i W$, recorded in $\mathrm{KCl} 0.1 \mathrm{~mol} . \mathrm{L}^{-1}$ at $0.1 \mathrm{~V} \mathrm{~s}^{-1}$

The electrochemical response of $P P y / S i W$ film consisted in a first oxidation/ reduction pair at $\mathrm{E}_{\mathrm{p} / 2}=-0.69 \mathrm{~V}$ on top of a large current connected to the partial redox transformation of the polymeric film itself. The second peak at $\mathrm{E}_{\mathrm{p} / 2}=$ $0.14 \mathrm{~V}$ has been previously established that this redox process corresponds at the oxidation/reduction reaction of the electroactive anion silicotungstate $\left.\left[\left(\mathrm{SiW}_{12} \mathrm{O}_{40}\right)^{3-} /\left(\mathrm{SiW}_{12} \mathrm{O}_{40}\right)^{4-}\right)\right]$ entrapped inside the polymer film (figure 2_d $)^{18}$. The $\mathrm{E}_{\mathrm{p} / 2}$ values obtained when using $\mathrm{KCl}$ as electrolyte are summarised in Table 1 . 
Table I. Peak potentials of the electrochemical response of $P P y$ films doped with several doping agents immersed in $0.1 \mathrm{~mol} \mathrm{~L}^{-1} \mathrm{KCl}(\mathrm{pH}$ 6.5) and carried out at sweep rate of $0.1 \mathrm{~V} \mathrm{~s}^{-1}$.

\begin{tabular}{|l|c|c|c|c|c|c|}
\hline \multirow{2}{*}{ Polymer } & \multicolumn{2}{|c|}{$\begin{array}{c}\text { Process I } \\
\text { (E/V vs Ag/AgCl) }\end{array}$} & & \multicolumn{2}{c|}{$\begin{array}{c}\text { Process II } \\
\text { (E/V vs Ag/AgCl) })\end{array}$} & \\
\cline { 2 - 7 } & cathodic & Anodic & $\mathrm{E}_{\mathrm{p} / 2}$ & cathodic & Anodic & $\mathrm{E}_{\mathrm{p} / 2}$ \\
\hline $\mathrm{PPy} / \mathrm{DBS}$ & -0.72 & -0.54 & -0.63 & -0.16 & -0.14 & -0.15 \\
\hline $\mathrm{PPy} / \mathrm{NDS}$ & -0.63 & -0.41 & -0.52 & 0.04 & 0.11 & 0.09 \\
\hline $\mathrm{PPy} / \mathrm{SO}_{4}$ & -0.63 & -0.40 & -0.51 & -0.11 & -0.09 & -0.10 \\
\hline $\mathrm{PPy} / \mathrm{Si} W$ & -0.55 & -0.29 & -0.69 & 0.05 & 0.24 & 0.14 \\
\hline
\end{tabular}

The cyclic voltammograms of the electroactive polypyrrole films are remarkably different depending of the doping agent used. This difference may be explained by differences in association between doping agent and the $P P y$ films. The above results indicate that the shape and position of the peaks depend on the nature of the doping anion.

The dynamic character of the oxidation/reduction process for electroactive polypyrrole doped with several doping agent was further examined, for this purpose, the effect of the sweep rate on the performance of polypyrrole films immersed in $\mathrm{KCl}$ was studied. The figure 3 displays the sweep rate dependence of the anodic and cathodic peaks current (process I) for the $P P y / N D S, P P y /$ $\mathrm{SO}_{4}$ and $\mathrm{PPy} / \mathrm{SiW}$ films immersed in $\mathrm{KCl} 0.1 \mathrm{~mol} \mathrm{~L}^{-1}$ aqueous solution, the process I is more electroactive than process II and that is the reason why it was selected as reference. In all cases an increase in the sweep rates influences the voltammetric response causing an increase in peaks current intensity and the peak-to-peak separation $\left(E_{2}\right)$. For sweep rates between 0.025 and $0.20 \mathrm{Vs}^{-1}$ the current varies linearly as predicted theoretically for absorbed species of film with thin-layer behavior ${ }^{19}$. Also, it is worthily noting that in the case of the $P P y / N D S$ films, the linear relation between peak current and the sweep rate was approximately 2.5 times upper that $\mathrm{PPy} / \mathrm{SO}_{4}$ and this 1.3 times higher that $\mathrm{PPy} / \mathrm{SiW}$ film. This result indicates that in comparison with the $P P y / \mathrm{Si} W$ film, the $\mathrm{PPy} / \mathrm{SO}_{4}$ have a faster dynamic character and the $\mathrm{PPy} / \mathrm{NDS}$ film shown an fastest dynamic character in the redox process. This behavior should be related with the better molecular ordering in the $\mathrm{PPy} / \mathrm{NDS}$ and $\mathrm{PPy} / \mathrm{SO}_{4}$ films configuration due to its slower polymerization rate generated by the doubly charge ${ }^{20}$. It can be concluded that the kinetic process in the electrochemical response of the $P P y$ films depends on the ability of the films to exchange ions with the electrolyte, which is affected by kind doping agent entrapped inside the $P P y$ films during the electropolymerization process.

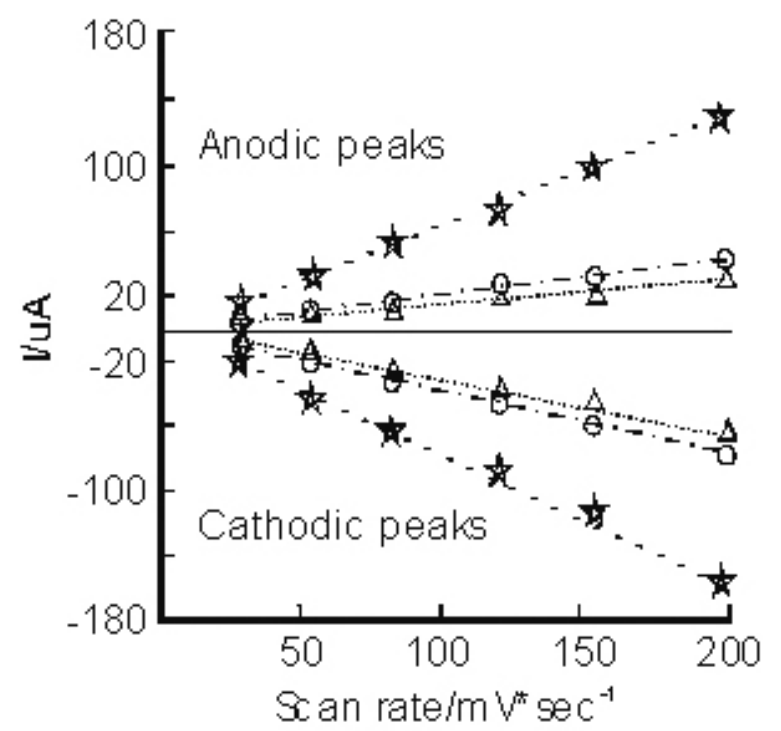

Figure 3. Dependence of the anodic and cathodic peaks current of the wave process I on sweep rate for: $(\triangle) P P y / S i W$, (o) $P P y / S O$ and ( $) P P y /$ $N D S$; recorded in $\mathrm{KCl} 0.1 \mathrm{~mol} \mathrm{~L}^{-1}$ solution.

\section{Influence of doping agent concentration}

The influence of the doping agent concentration in the electrochemical behavior and kinetic of formation was evaluated as follows. PPy films were polymerized at a fixed potential of $0.8 \mathrm{~V}$ using a pyrrole concentration of 0.2 mol L-1 with a doping electrolyte $\left(\mathrm{H}_{2} \mathrm{SO}_{4}\right)$ concentrations ranging from 0.05 to $0.3 \mathrm{~mol} \mathrm{~L}^{-1}$. All the films have same thickness of ca. $1 \mu \mathrm{m}$, which was estimated by using Faraday's law (based on the electrical consumption to obtain the deposit), where $\mathrm{Q}$ is the specific area overall charge for electrodeposition $\left(\mathrm{C} \mathrm{m}^{-}\right.$ ${ }^{2}$ ), and assuming (i) a two-electron mechanism based on the monomer molecule implied in the process; (ii) the current efficiency is $100 \%$; (iii) a $P P y$ density $(\rho)$ of $1500 \mathrm{Kg} \mathrm{m}^{-3}$ and a pyrrole molar mass $(M)$ of $67 \times 10^{-3} \mathrm{Kg} \mathrm{mol}^{-1}{ }^{(13)}$.

$$
d_{n}=\frac{Q M}{2 F \rho}
$$

The chronoamperograms recorded (figure 4) showed the characteristic stepped features: a current density jump (zone I) attributed to several process such as the charge of the double layer, the oxidation of the metallic electrode due to the aqueous medium and the monomer oxidation, in the second part (zone II) the nucleation phenomena takes place, and the third part (zone III) shows the continuous and gradual polymer growth. The first part of the curves (zone I), that is, the induction time, was dependent on the doping agent concentration, as can be seen in the figure 4 , a higher concentration of doping agent favor diffusion and a lower induction time is achieved. On the other hand, the nucleation (zone II) is too effected; so, the time consumed by the nucleation process was longer at a lower concentration. This suggests that the charge transfer was the limit step in the process of growth in the zone II. In addition, the electropolymerization charge increase gradually with increasing doping agent concentration. This phenomena is expected since the increasing electrolyte can reduce the overall resistance of the system and the high doping agent concentration favor the polymeric growth. Moreover, the polymerization charge $\left(Q_{p}\right)$ showed a relationship with the doping agent concentration $\left[\mathrm{SO}_{4}{ }^{2}\right]$ : $Q(m C)=13.85\left[S^{2}{ }^{2}\right]^{0.5} ;\left(r^{2}=0.988 ; n=5\right)$. This dependence related to the doping agent suggests the participation of the anions in the polymerization mechanism; as well as to reduce the resistance of the system, the anion (i.e doping agent) can to stabilize the monomeric cation radical, once it is formed, allowing its interaction with a new monomeric radical. These phenomena indicate that the doping agent concentration have a role in the polymerization rate and hence the electrochemical properties from resulted polymer.

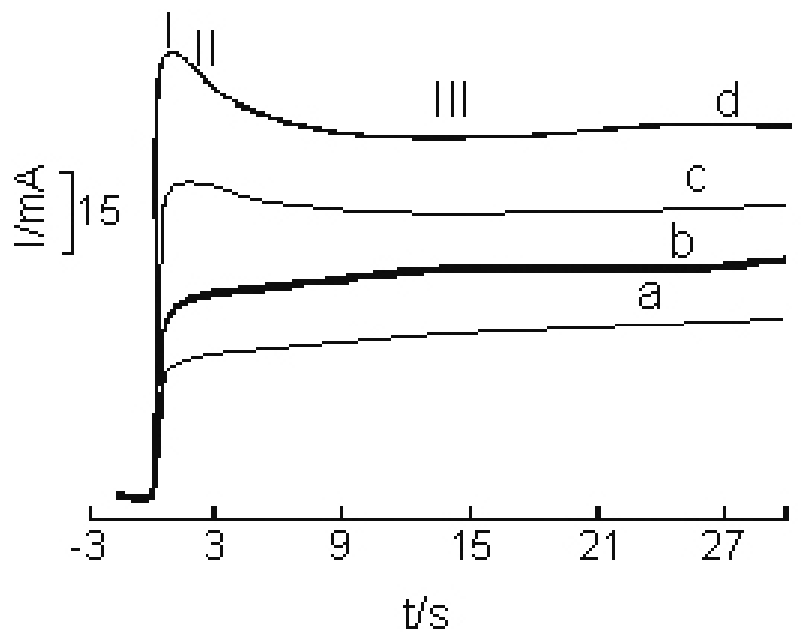

Figure 4. Chronoamperograms of polymerization of $\mathrm{PPy} / \mathrm{SO}_{4}$ at various doping agent concentrations: a) 0.05 mol. $\mathrm{L}^{-1}$, b) $0.1 \mathrm{~mol} . \mathrm{L}^{-1}$, c) $0.15 \mathrm{~mol} . \mathrm{L}^{-1}$, d) $0.3 \mathrm{~mol} . \mathrm{L}^{-1}$; pyrrole concentration $0.2 \mathrm{~mol} \mathrm{~L}^{-1}$ and potential $0.8 \mathrm{~V}$.

The cyclic voltammograms for films prepared using electrolytes having different concentrations were obtained and the experiments were carried out in $\mathrm{KCl} 0.1 \mathrm{~mol} \mathrm{~L}^{-1}$ aqueous solution, from -1.0 to $0.5 \mathrm{~V}$ at a sweep rate of $0.1 \mathrm{~V} \mathrm{~s}^{-1}$. The PPy films responses are shown in figure 5. It can be seen that 
the peaks current are slight higher when the doping agent concentration are 0.15 and $0.3 \mathrm{~mol} \mathrm{~L}^{-1}$ (curves $\mathrm{c}$ and d). Thus, while the voltammetric behavior for low concentration of doping agent $\left(0.05\right.$ and $0.1 \mathrm{~mol} \mathrm{~L}^{-1}$, curves $\mathrm{a}$ and $\mathrm{b}$ respectively) seemed to have identical response, those of 0.15 and $0.3 \mathrm{~mol} \mathrm{~L}^{-1}$ differed in the width and peaks potentials; for low concentration $(0.05$ and 0.1 $\mathrm{mol} \mathrm{L}^{-1}$ ), the peaks becomes sharper, while at highest concentration the peaks are broader. In addition, for low concentration the anodic and cathodic peaks trend to lower potentials.

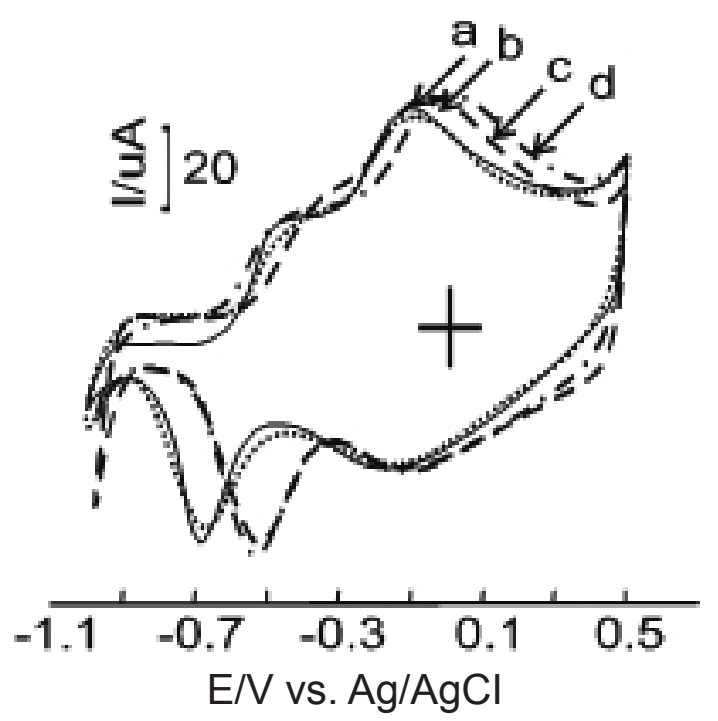

Figure 5. Cyclic voltammetry of $\mathrm{PPy} / \mathrm{SO}_{4}$ polymerized in different concentrations of doping agents recorded in $\mathrm{KCl} 0.1 \mathrm{~mol} \mathrm{~L}^{-1}$ at sweep rate of $0.1 \mathrm{~V} \mathrm{~s}^{-1}$ : a) $0.05 \mathrm{~mol} . \mathrm{L}^{-1}$, b) $0.1 \mathrm{~mol} . \mathrm{L}^{-1}$, c) $0.15 \mathrm{~mol} . \mathrm{L}^{-1}$, d) $0.3 \mathrm{~mol} . \mathrm{L}^{-1}$

On the other hand, under successive cycling, the intensity of the peaks in the voltammograms decrease progressively, under continuous cycling (100 cycles) the peak current intensity of the films generated with different doping agent concentration were practically similar (ca. $9.5 \%$ ). Therefore, it can be concluded that the doping agent concentration influence was marked only in the electrochemical response and growth rate but did not have a deep effect on the stability, these can be due to that the concentration ranging experimented no produce very significant changes on the polymeric structure on the film.

\section{Influence of monomer concentration}

In order to determine the effect of monomer concentration, the concentration of doping agent $\left(\mathrm{H}_{2} \mathrm{SO}_{4}\right)$ and the applied potential were kept constant at $0.1 \mathrm{~mol}$ $\mathrm{L}^{-1}$ and $0.8 \mathrm{~V}$, respectively. The electrochemical syntheses were performed at monomer concentrations of 0.1 to $0.5 \mathrm{~mol} \mathrm{~L}^{-1}$ (all the films have same calculated thickness of ca. $1 \mu \mathrm{m}$ ). The chronoamperograms obtained were highly reproducible and it was observed that the concentration of pyrrole effected the induction time (figure 6). Thus, the first step of the electropolymerization is the diffusion of the pyrrole monomer to the electrode surface, therefore, the rate of the reaction was determined by the amount of monomer available at the interface of electrode/solution. So, for higher monomer concentration, the positive charge on the working electrode is rapidly consumed by pyrrole, in order of maintain the potential the accumulation of the charge at the electrode is higher. Thus, an increase in the density charge of polymerization is achieved with higher pyrrole concentration. The polymerization charge $(Q)$ was related to the monomer concentration $[P y]: Q_{p}(m C)=18.14[P y]^{0.85} ;\left(r^{2}=0.995 ; n=6\right)$.

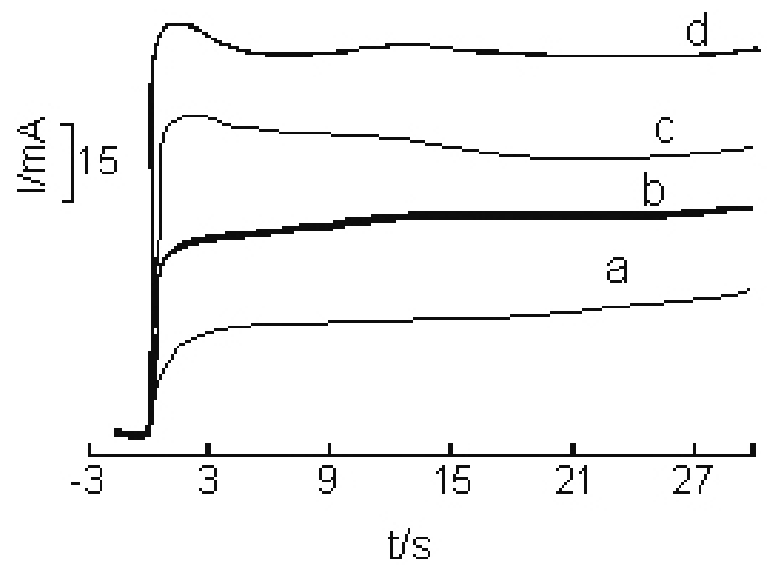

Figure 6. Chronoamperograms of polymerization of $\mathrm{PPy} / \mathrm{SO}_{4}$ at various pyrrole concentrations: a) 0.1 mol.L-1 , b) 0.2 mol.L ${ }^{-1}$, c) 0.3 mol.L ${ }^{-1}$, d) $0.5 \mathrm{~mol}$. $\mathrm{L}^{-1}$. doping agent concentration $0.1 \mathrm{~mol} \mathrm{~L}^{-1}$ and polymerization potential $0.8 \mathrm{~V}$.

The cyclic voltammetric responses obtained with the polypyrrole films generated with several pyrrole concentrations are given in the figure 7 . The responses obtained from films synthesized with monomer concentration of 0.1 and $0.2 \mathrm{~mol} \mathrm{~L}^{-1}$ seemed analogous behavior (similar position and current of peak). The current of peak (i.e. area of the curve) of the curves obtained from 0.3 and $0.5 \mathrm{~mol} \mathrm{~L}^{-1}$ are slight higher compared with the peaks current for the films formed with 0.1 and $0.2 \mathrm{~mol} \mathrm{~L}^{-1}$. The first redox process (anodic and cathodic peaks) moves to the right of the potential scale (positive potential). Additionally, after of 100 consecutives switching, the decreasing of the peak current intensity was higher (about 12\%) for the films generated at higher monomer concentration $\left(0.3\right.$ and $\left.0.5 \mathrm{~mol} \mathrm{~L}^{-1}\right)$ while that the films obtained at lower concentration $\left(0.1\right.$ and $\left.0.2 \mathrm{~mol} \mathrm{~L}^{-1}\right)$ the peak current decreasing was smaller (about 9\%). So, the best stability in the electrochemical response was found for pyrrole concentrations in the range of 0.1 and $0.2 \mathrm{~mol} \mathrm{~L}^{-1}$. This behavior can be explained by the fact that to higher concentrations of monomer (pyrrole) the polymerization rate is more disarrayed, producing a polymeric films more compact, in consequence the films are enable the leaving of the doping anion during the voltammetric switching. This behavior has been reported by other authors ${ }^{21}$.

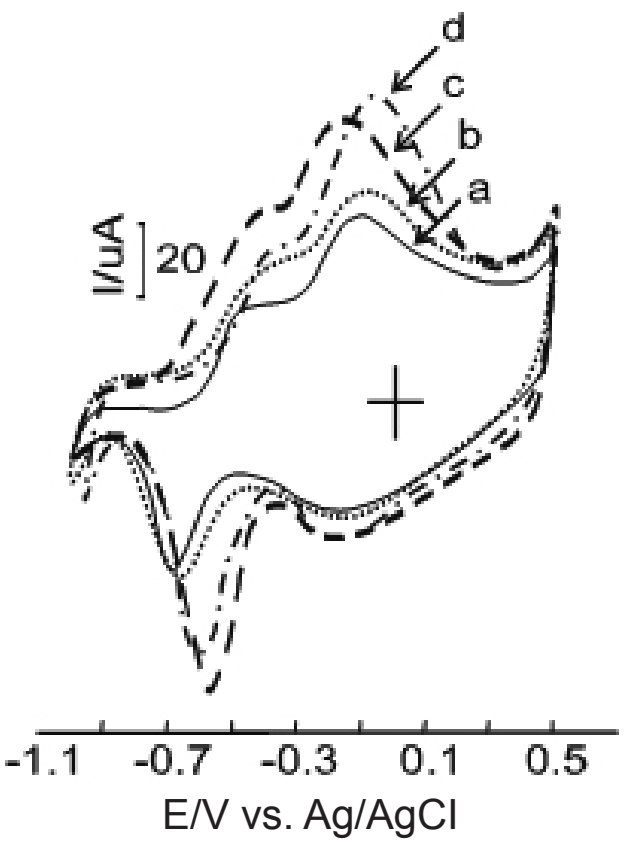

Figure 7. Cyclic voltammetry of $P P y / S O$ polymerized in different concentrations of pyrrole recorded in $\mathrm{KCl} 0.1 \mathrm{~mol} \mathrm{~L}^{-1}$ at sweep rate of $0.1 \mathrm{~V}$ $\mathrm{S}^{-1}$. 


\section{Influence of the deposition time (i.e film thickness)}

Since film thickness is controlled by the electropolymerization time; different films were fabricated varying the deposition time and the effect of the thickness in the polymeric properties and kinetic of formation of the films was studied. In order to obtain PPy films with different thickness, the electrochemical synthesis was performed at $0.8 \mathrm{~V}$ from $0.2 \mathrm{~mol} \mathrm{~L}^{-1}$ pyrrole concentration and $0.1 \mathrm{~mol} \mathrm{~L}^{-1}$ doping agents at polymerization times of 5 to 120 s. As expected, a linear relationship was found between the calculated areas under the curves (electropolymerization charge $Q_{p}$ ) and the polymerization times $\left(t_{p}\right):[P y]: Q(m C)=0.623+0.236 t(s) ;\left(r^{2}=0.987 ; n=6\right)$.

The electrochemical behavior of $P P y$ films resulting from the polymerization at different time was investigated in $0.1 \mathrm{~mol} \mathrm{~L}^{-1} \mathrm{KCl}$ aqueous solution. The effect of film thickness is illustrated in Figure 8, it can be observed that the film thickness has an effect on the peak current magnitudes; this is expected as with the increasing film thickness surface area increases almost regularly. In addition, the deposition time seemed to affect as well the peak potentials values, the anodic and cathodic peak potential shift very slightly in the opposite direction with the enhance of the films thickness. The morphology changes to more globule structure with increase the thickness of the films ${ }^{18}$ and therefore the electrochemical activity can occur at different interfaces: contacts of electrolyte solution with the external and internal surface of polymer. This may explain the increase of the splitting of anodic and cathodic peaks $\left(E_{P / 2}\right)$ with the thickness film. The stability study of the $P P y$ films response indicated that thin films were less stable under continuous cycling.

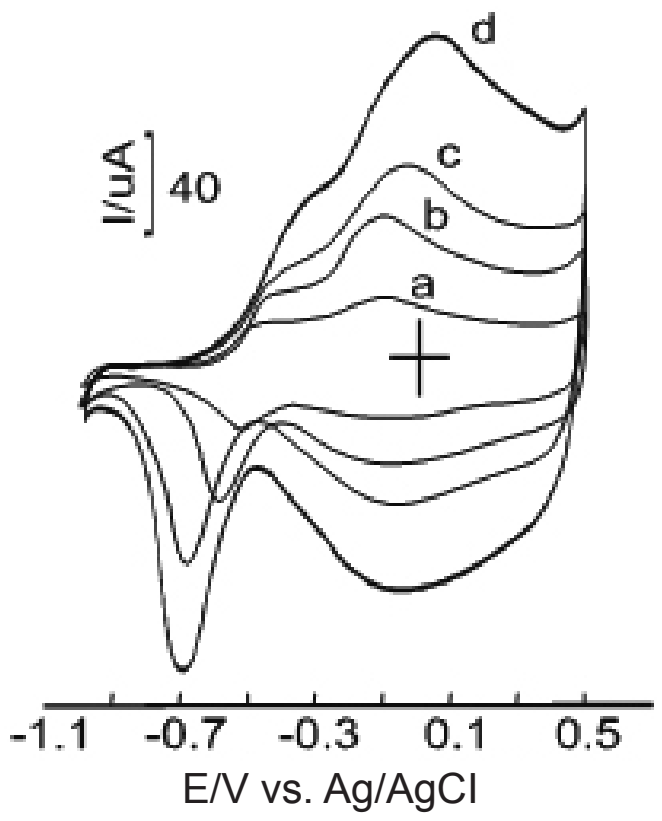

Figure 8. Cyclic voltammograms recorded in $\mathrm{KCl} 0.1 \mathrm{~mol} \mathrm{~L}^{-1}$ of $P P y / S O$ obtained with different polymerization time: a) $10 \mathrm{~s}$, b) $30 \mathrm{~s}$, c) $60 \mathrm{~s}$ and d) $120 \mathrm{~s}$.

\section{Potential limit of polymerization}

The effect of potential limit was investigated with $0.2 \mathrm{~mol} \mathrm{~L}^{-1}$ pyrrole concentration and $0.1 \mathrm{~mol} \mathrm{~L}^{-1}$ doping agent. All the films have the same thickness of ca. $1 \mu \mathrm{m}$ and the polymerizations were carried out at a ranging of potential of 0.7 to $1.0 \mathrm{~V}$ (the polypyrrole films did not grow sufficiently when low positive potential, such as $+0.6 \mathrm{~V}$ are employed). The polymerization efficiency improved as the polymerization potential become more positive, for instance, when the potential is $0.9 \mathrm{~V}$, the polymerization rate is approximately 1.3 times faster than in the case of the $0.8 \mathrm{~V}$. So, the polymerization charge $(Q p)$ showed a linear relationship with the polymerization potential $(E p)$ : $Q_{p}(m C)=-11.88+020.5 E_{p}(V) ;\left(r^{2}=0.993 ; n=5\right)$.

The potential used for the polymeric synthesis affects the charge of the electrochemical polymerization process and the kinetic of films formation, consequently the potential should influence the properties of the polypyrrole films. The electrochemical response of films formed at different anodic potentials were studied in $0.1 \mathrm{~mol} \mathrm{~L}^{-1} \mathrm{KCl}$ solution by cyclic voltammetry with a scan range from -1.0 to $0.5 \mathrm{~V}$ at sweep rate of $0.1 \mathrm{~V} \mathrm{~s}^{-1}$. As can be observed in figure 9 , (Only three signals have been plotted for clarity) all voltammograms have well defined sharp anodic and cathodic peaks. For low potential $(0.7$ $\mathrm{V}$, curve a) the peaks are better defined and less broad, in addition when the polymerization potential are higher the peaks shifts towards higher potential. In other hand, the voltammetric peak current decrease with the films have been polymerized at higher potential. It is well known that polypyrrole films can be overoxidized at high positive potential, therefore the electrochemical behavior observed in the cyclic voltammograms can be explained by the oxidation of the polypyrrole chain during the polymerization experiment. This confirms that the potential used during polymerization has a strong influence on the electrochemical properties of the resulting polymer and that the films formed with high potential may be less conjugated due at partial degradation process, therefore, the polypyrrole lost electrochemical activity at higher potential limit due to overoxidation. Similar behavior has been reported in the literature for polythiophene derived ${ }^{22}$.

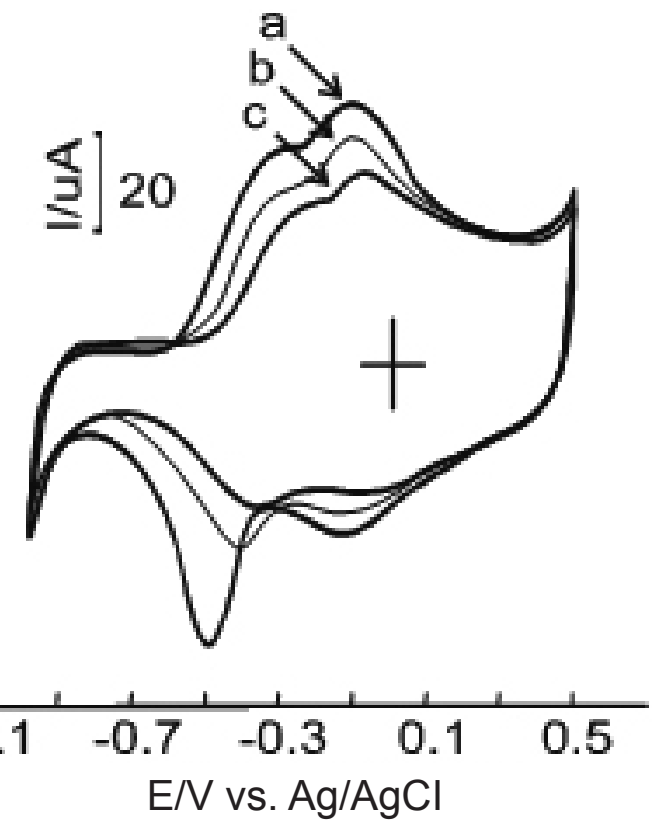

Figure 9: Cyclic voltammograms recorded in $\mathrm{KCl} 0.1 \mathrm{~mol} \mathrm{~L}^{-1}$ of $P P y$ films polymerized at: a) $0.7 \mathrm{~V}$, b) $0.8 \mathrm{~V}$ and c) $0.9 \mathrm{~V}$.

\section{CONCLUSIONS}

The parameters used during the electrochemical synthesis played crucial roles in the kinetic behavior of electropolymerization process and electrochemical properties of the polypyrrole film. The concentration of doping agent affect the electrochemical formation and voltammetric response of the $P P y$ films so, the films polymerized in high concentration of doping agent, more polymer films is obtained and the induction time is higher, also at higher concentration the voltammograms shown more broad and positive potential peaks. The polymerization potential affected the formation and the structure of the polypyrrole backbone; the film that was synthesized with low potential $(0.7$ and $0.8 \mathrm{~V}$ ) seemed to be perfect with higher conjugation and therefore a higher level of electroactivity than those films synthesized with high potential ( 0.9 and $1.0 \mathrm{~V})$. The voltammetric behavior at higher polymerization potential lower intensity was shown in the signals (i.e. voltammograms). The films thickness affected the intensity of the current due to the increase of the area of $P P y$ film, in addition, the $\mathrm{E}$ was higher increasing the films thickness. The doping agent had a strong influence in the electropolymerization process (induction time, nucleation and growing) of polymer films. Therefore, the electrochemical response was remarkably different. 


\section{REFERENCES}

1. M. Li, Y. Guo, Y. Wei, A. MacDiarmid, P. Lelkes, Biomaterials 27, 2705, (2006)

2. S. Brady, K. Lau, W. Megill, G. Wallace, D. Diamond, Synth. Met. 154, $25,(2005)$

3. F. Brovelli, B. Rivas, J. Berneve, J. Chil. Chem. Soc. 52, 1065, (2007)

4. A. Arrieta, C. Apetrei. M. Rodríguez-Méndez, J. De Saja, Electrochim. Acta. 49, 4543, (2004)

5. A. Arrieta, V. Parra, J. Fernández-Escudero, M. Iñiguez, J. De Saja, M. Rodríguez-Méndez, Anal. Chim. Acta. 563, 229, (2006)

6. A. Michalska, K. Maksymiuk, Talanta 63, 109, (2004)

7. C. Park, Y Sun, D. Kim, Electrochim. Acta. 50, 375, (2004)

8. S. Chung, T. Wen, A. Gopalan, Mater. Sci. Eng. B. 116, 125, (2005)

9. A. Cambra, M. Redondo, M. Gonzalez-Tejera, Synth. Met., 139, 21, (2003)

10. R. Murugesan, E. Subramanian, Mater. Chem. and Phys. 80, 731, (2003)

11. S. Jönsson, J. Birgerson, X. Crispin, G. Greczynski, W. Osikowicz, A. van der Gon, W. Salaneck, M. Fahlman, Synth. Met. 139, 1, (2003)
12. G. Garcia-Belmonte, Electrochem. Commun. 5, 236, (2003)

13. K. Kanazawa, A. Diaz, W. Gill, P. Grant, G. Street, G. Gardini, J. Kwak, Synth. Met. 1, 329, (1980)

14. A. Arrieta, R. Vieira, J. Chil. Chem. Soc. 51, 971, (2006)

15. G. Appel, O. Böhme, R. Mikalo, D. Schmeißer, Chem. Phys. Lett., 313, 411, (1999)

16. M. Levi, C. Lopez, E. Vieil, M. Vorotyntsev, Electrochim. Acta. 42, 757, (1997)

17. C. Zhao, Z. Jiang, Appl. Surf. Sci. 229, 372, (2004)

18. T. Vernitskaya, O. Efimov, Russ. Chem. Rev. 66, 443, (1997)

19. S. Song, K. Park, W. Kim, S. Chang, Mater. Sci. and Eng. C. 24, 225 , (2004)

20. J. Tamm, A. Hallik, A. Alumaa, V. Sammelselg, Electrochim. Acta, 42, 2929, (1997)

21. S. Yi Chu, P. Kilmartin, S. Jing, G. Bowmaker, R. Cooney, J. TravasSejdic, Synth. Metals 158, 38, (2008)

22. X. Du, Z. Wang, Electrochim. Acta. 48, 1713, (2003) 